\title{
Shape of Large Bound Polysomes in Cultured Fibroblasts and Thyroid E pithelial Cells
}

\author{
A. KENT CHRISTENSEN* AND CAROL M. BOURNE \\ Department of Anatomy and Cell Biology, \\ The University of Michigan Medical School, Ann Arbor, Michigan 48109-0616
}

\begin{abstract}
Large bound polysomes were observed by conventional electron microscopy in surface or en face views of the rough endoplasmic reticulum (RER) in two cultured cell types. Cultured thyroid follicular epithelial cells and dermal fibroblasts, both from rats, were prepared for electron microscopy. Ultrathin sections were cut in the plane of the flattened cells to maximize the incidence of RER surface views. Some observations were also made on tissue sections of rat thyroid. Most of the large, RER-bound polysomes in both cell types appeared as two parallel rows of ribosome, thus resembling the shape of long hairpins, although probably closed at both ends. The two parallel rows of ribosomes were about $14 \mathrm{~nm}$ apart, and the center-to-center distance between ribosomes in the strands averaged $25 \mathrm{~nm}$. Most of the large bound polysomes in thyroid epithelial cells were presumably making thyrogl obul in subunits ( $330 \mathrm{kDa}$ ), while a majority of those in the fibroblasts were probably making prepro- $\alpha$ chains of collagen I (150 kDa). It was not possible in this material to see complete large polysomes, because their size usually caused them to extend out of the plane of section. In addition to the hairpin polysomes, there were smaller numbers of other forms. A characteristic large spiral polysome was seen occasionally in both cell types and contained as many as 31 ribosomes. One or two dense particles were sometimes seen in the center of spiral or circular polysomes. The consistent hairpin shape of most large bound polysomes observed in this study suggests that their shape is quite stable. Anat Rec 255:116-129, 1999. @ 1999 Wiley-Liss, Inc.
\end{abstract}

Key words: polysomes; ribosomes; electron microscopy; fibroblasts; thyroid; thyroglobulin; collagen; rats; culture

Polysomes for the synthesis of secretory, Iysosomal and integral membrane proteins are bound to membranes of the RER. As illustrated in Fig. 1, it is possible to observe the shape of bound polysomes, and the number of ribosomes they contain, in conventional electron micrographs of cells when the membranes of the RE R happen to be seen in surface or en face view (shown diagramatically at right in Fig. 1), rather than in the usual membrane cross sections (as shown on left side of Fig. 1). When observed in surface view, the ribosomes of bound polysomes are arranged like beads on a string, forming characteristic shapes, such as circles, spirals, loops, or hairpins. These patterns, first described by Palade (1955), can be studied to characterize the population of bound polysomes in a particular cell type (K itani et al., 1982; Christensen et al., 1987). In the present study, we are concerned with bound polysomes that make particu- larly large proteins, focusing on two cell types: the thyroid follicular epithelial cell and the fibroblast.

Grant sponsor: National Institutes of Health; Grant number: HD-11311 to AKC.

This work was also supported by National Institutes of Health Biomedical Research Support Grant funds.

Portions of this work have been presented previously in two abstracts, one on cultured thyroid follicular cells (Christensen and Coon, 1990), and the other on cultured fibroblasts (Christensen, 1991).

*Correspondence to: Dr. A. Kent Christensen, Department of Anatomy and Cell Biology, Medical Science II Building, University of Michigan Medical School, Ann Arbor, MI 48109-0616. Fax: 734-763-1166; E-mail: akc@umich.edu

Received 21 September 1998; Accepted 4 J anuary 1999 


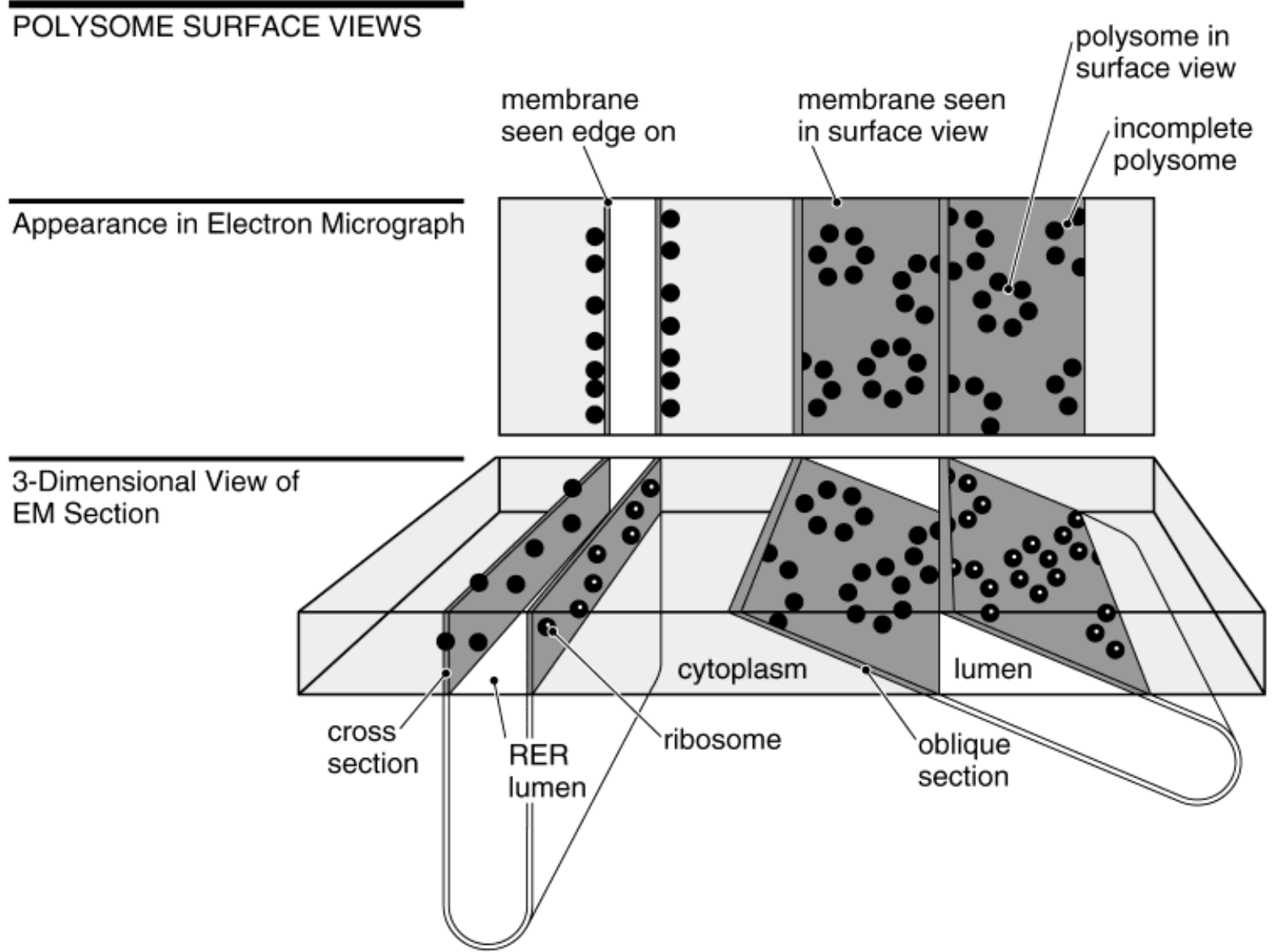

Fig. 1. Diagram illustrating the nature of polysome surface views observed in this study. The RER is usually seen in electron micrographs as two membranes studded with ribosomes, as is shown at upper left in the diagram. This appearance results from the RER membranes being seen edge-on (lower left). On the other hand, the section sometimes passes obliquely through the RER cisterna (lower right) and the view in the electron micrograph (upper right) then shows the shape and size of the bound polysomes (shown as circular polysomes in this example). The number of ribosomes in the polysomes can be counted. Some of the polysomes are incomplete, because they occur where the RER membrane is passing out of the plane of section. This is why the large hairpin polysomes of the present study are virtually never seen in their entirety, since they inevitably extend out of the section plane.
The principal secretory product of thyroid follicular epithelial cells is thyroglobulin, a large glycoprotein composed of two identical $330 \mathrm{kDa}$ subunits (Malthièry et al., 1989). Cultured dermal fibroblasts, stimulated with ascorbate, would secrete predominantly type I collagen ( $\alpha 1$ and $\alpha 2$ chains), as well as some type III collagen (see Discussion section). The cells may also secrete smaller amounts of other collagens, fibronectin, tropoelastin, fibrillin, and other products.

Our observations on fibroblast polysome surface views expand on earlier reports by Palade (1958) and by Ross and Benditt (1964), in which "parallel rows of ribosomes" were described in tissue fibroblasts. A previous ultrastructural study on thyroid polysomes in sheep thyroid (Keyhani, 1969) was concerned with ribosomal number in the polysomes, and although electron micrographs of polysomes were included, no mention was made of polysomal shape (see Discussion section).

We have utilized cultured cells for the present study because the RER tends to be oriented in the plane of these flattened cells, greatly increasing the likelihood of seeing clearcut polysomal surface views in electron microscope (EM) sections that have been cut in that plane.

\section{Cell Cultures}

\section{MATE RIALS AND METHODS}

Cultured thyroid follicular cells, FRTL strain (AmbesiImpiombato et al., 1980), were kindly provided by Dr. Hayden G. Coon of the Laboratory of Genetics, National Cancer Institute, NIH, in Bethesda, MD. The FRTL strain was derived originally from a primary culture of rat thyroid and was maintained on a modified Ham's F-12M medium, supplemented with $0.5 \%$ calf serum and six hormones or growth factors. During years of subsequent continuous culture, the cells retained the ability to secrete physiological amounts of thyroglobulin and al so to concentrate iodide by $100-$ fold. Cells of the original FRTL strain, used here, are particularly advantageous for the present study because they tend to be flatter than the subsequent FRTL-5 cell line (Ambesi-I mpiombato and Perrild, 1989), which is more widely used today. 
Cultures of rat dermal fibroblasts were kindly provided by Dr. Donald K. MacCallum of the Department of Anatomy and Cell Biology, University of Michigan Medical School. The cells were derived from primary skin explants from $125 \mathrm{~g}$ male Charles River CD rats. The cells were maintained in Eagle's Minimal Essential Medium with $10 \%$ fetal calf serum and $50 \mu \mathrm{g} / \mathrm{ml}$ gentamicin sulfate. After one passage the cells were subcultured. When they reached confluence in two to three days, they were fed with medium containing $50 \mu \mathrm{g} / \mathrm{ml}$ sodium ascorbate to stimulate collagen production (Pinnell, 1985). The medium was changed after $24 \mathrm{~h}$, and ascorbate was readmi nistered $12 \mathrm{~h}$ later, just before the cells were fixed.

Both cell types were cultured in 96-well plates (flatbottom wells), to facilitate later processing for electron microscopy.

\section{E M Preparation}

The method used to fix, dehydrate, and embed the cultures for electron microscopy was adapted from that described by J epsen et al. (1980). Briefly, the culture medium in the 96-well plates was removed and rapidly replaced with cold fixative. The fixative for the thyroid cells was a freshly-prepared mixture of $1.25 \%$ glutaraldehyde and $1 \%$ osmium tetroxide ( $2 \mathrm{hr}$ fixation at $4^{\circ} \mathrm{C}$ ), while the fibroblasts were fixed for $1 \mathrm{hr}$ with cold $1.25 \%$ glutaraldehyde, and were subsequently postfixed $1 \mathrm{hr}$ at $4^{\circ} \mathrm{C}$ in $1 \%$ osmium tetroxide. The fixatives were buffered with $0.1 \mathrm{M}$ sodium cacodylate ( $\mathrm{pH}$ 7.4), which also contained $1 \mathrm{mM}$ $\mathrm{CaCl}_{2}$. Following fixation, the cells were washed with buffer, and then dehydrated with increasing concentrations of ethanol, still in the 96-well plates. Propylene oxide was not used for infiltration, since it would have dissolved the plastic of the wells, releasing the cells. Instead, the wells were filled with a 1:1 mixture of ethanol:EponAraldite for $2 \times 1 \mathrm{~h}$, followed by two changes of EponAraldite on a rotator, the second change lasting overnight. For final embedding the wells were filled with EponAraldite (Mollenhauer, 1964), and polymerization was carried out at $60^{\circ} \mathrm{C}$. The resulting polymerized block in each of the wells thus had the monolayer of cultured cells at its lower face.

The plastic blocks were removed from the wells of the 96-well plates by a combination of rapid cooling with liquid nitrogen and pressure applied with pliers to break the walls of the wells. Ultrathin sections of light gold interference color, cut in the plane of the cell monolayer, were mounted on EM grids, and were then stained with uranyl acetate and lead citrate (Reynolds, 1963).

Stained sections of cultured cells were viewed with a Philips EM 201 el ectron microscope used at $60 \mathrm{kV}$. Most of the micrographs of polysome fields were taken at an original magnification of 20,000x. Magnifications were checked with a diffraction grating replica.

Thyroid tissue was fixed by perfusion with $2.5 \%$ glutaraldehyde (buffered with s-collidine), postfixed in $1.3 \%$ osmium tetroxide, and embedded in Epon-Araldite. The detailed procedure was described in our earlier study (Christensen et al., 1987). Observations on thyroid tissue cells were madewith a Philips E M 400 el ectron microscope.

\section{Measurements}

The average center-to-center distance between ribosomes in hairpin polysomes was measured on prints, utilizing relatively straight and clearcut portions of the polysomes. The distance between strands in the polysome was measured from the inner ends of the ribosomes in adjacent strands. A $7 \times$ magnifier fitted with a $20 \mathrm{~mm}$ graduated reticle (Bausch \& Lomb) was used for all measurements. Lengths measured on prints were divided by the magnification to yield the actual length. It should be pointed out that these measurements were probably slightly underestimated, since the polysomes were often oriented somewhat obliquely within the section (see Fig. 1 ), and so were not observed in full surface view.

It was difficult to make meaningful relative polysome counts for hairpin, spiral, and circular polysomes, since the long hairpin polysomes usually tended to extend out of the plane of section, and would thus be present in multiple sections, causing them to be substantially over-estimated compared to smaller polysomes that were more compact. In addition, the membranes were lightly stained in these preparations, making it difficult to definethe gray outlines of RER membranes in surface view. It was therefore not possibleto estimate the number of polysomes per unit area of RER membrane.

\section{RESULTS}

The appearance of cells used in this study is illustrated in low power el ectron micrographs of a cultured fibroblast (Fig. 2) and of cultured thyroid follicular epithelial cells (Fig. 3). Areas of RER were common in the cytoplasm of both cell types. The gray rectangle in each figure indicates an area roughly comparable to that shown at higher magnification in Figs. 4 and 5 respectively.

Cytoplasm that exhibits abundant polysome surface views is shown in Fig. 4, from a cultured fibroblast, and in Fig. 5, from a cultured thyroid epithelial cell. The preponderant large polysomal form consists of two parallel strands of ribosomes, representing a hairpin-shaped polysome. The hairpin is often curved. Some characteristic examples of these hairpin polysomes are labeled with arrowheads in the figures. Occasional polysomes havethe shape of a large spiral and are labeled S in the figures. The lumen of the RER (labeled with asterisks) is usually cut obliquely, and appears gray in Fig. 4 because of the abundant secretory proteins it contains. The membranes of RER and mitochondria in these preparations were not stained very densely, so tangential sections of RER membranes do not exhibit a grayish tone. Edge-on profiles of RER membranes are present in some instances (arrows), and are discerned mainly by the ribosomes on their surface.

\section{Polysomes: Hairpins}

Examples of hairpin polysomes, seen in surface view at higher magnification, are shown in Figs. 6 and 7, all at the same magnification. Those in Fig. 6 are from cultured fibroblasts, and those in Fig. 7 are from cultured (7A) and tissue (7B) thyroid follicular epithelial cells. The hairpin polysomes are similar in both cell types, consisting of two parallel rows of ribosomes, often with a visible closed end (arrowheads). The term "hairpin" aptly describes the general shape of these polysomes, and is used here for convenience. However, it seems likely that the hairpin polysome may actually be closed at both ends, but this cannot be established in the present material because the polysomes usually extend out of the plane of section; at that point the "end" appears open, but is not the actual end 




Figure 2. (Legend, overleaf.)

of the polysome. A branching hairpin (labeled $\mathrm{Br}$ in Fig. 7A) was seen on rare occasion.

The inset to Fig. 6 is a drawing depicting the likely appearance of a complete polysome for a prepro- $\alpha$ chain of collagen type I, which should be the most common large polysome on the RER in cultured fibroblasts. The inset is drawn in the same scale as the electron micrographs of that figure. A complete polysome for thyroglobulin would be about twice as long as the procollagen polysome (see Discussion).

The spacing between strands in the hairpin polysome is quite consistent for a given cell type and EM preservation. Measuring between the inner ends of the ribosomes, the interstrand distance averaged $11.0 \mathrm{~nm}( \pm 3.9 \mathrm{~nm} \mathrm{SD}, \mathrm{n}=$ 86) in the fibroblast material, $15.1 \mathrm{~nm}( \pm 4.7 \mathrm{~nm} \mathrm{SD}, \mathrm{n}=$ 82) in cultured thyroid cells, and $15.6 \mathrm{~nm}( \pm 4.5 \mathrm{~nm} \mathrm{SD}$, $\mathrm{n}=47$ ) in tissue thyroid cells. In the fibroblast material (F ig. 6), the strands were sometimes very close together, as if whatever maintained inter-strand distance was nolonger intact, perhaps because of less favorable EM preservation.

The spacing between ribosomes al ong the mRNA strand of the polysome is quite uniform. The center-to-center distance between ribosomes, measured along relatively straight portions of the hairpins, averaged $24.3 \mathrm{~nm}( \pm 2.7$ $\mathrm{nm} \mathrm{SD}, \mathrm{n}=147)$ in fibroblasts, $24.7 \mathrm{~nm}( \pm 2.6 \mathrm{~nm} \mathrm{SD}, \mathrm{n}=$ $175)$ in cultured thyroid cells, and $25.8 \mathrm{~nm}( \pm 3.9 \mathrm{~nm} \mathrm{SD}$, $\mathrm{n}=100$ ) in tissuethyroid cells.
There is often a suggestion that the ribosomes in adjacent strands of the hairpin polysomes are in register. Examples of this areend osed by thin brackets in Figs. 6 and 7 .

\section{Polysomes: Spirals and Other Forms}

In addition to the preponderant hairpin polysomes, other forms are also seen in lesser numbers on the RER. These include spiral and circular polysomes, shown at high magnification in Fig. 8, from cultured fibroblasts, and in Fig. 9, from cultured thyroid follicular epithelial cells.

One of the striking forms, seen occasionally in both cell types, is a large spiral polysome containing as many as 31 ribosomes. Examples of the large spirals are shown in Figs. 4 and 5, and are also seen at higher magnification in the upper two rows of Fig. 8 (fibroblast), and in the upper row of Fig. 9 (cultured thyroid). The inset to Figure 8 shows a drawing of such a spiral polysome, in the same scale as the el ectron micrographs.

Circular polysomes of various sizes are also observed, and examples are provided in the lower three rows of Fig. 8 (fibroblast) and lower two rows of Fig. 9 (thyroid).

A common feature of spiral and circular polysomes in both cell types is the presence of one or more particles in the center of the polysome that appear larger and denser than ribosomes. Examples of these particles are labeled with small arrows in Figs. 8 and 9. 


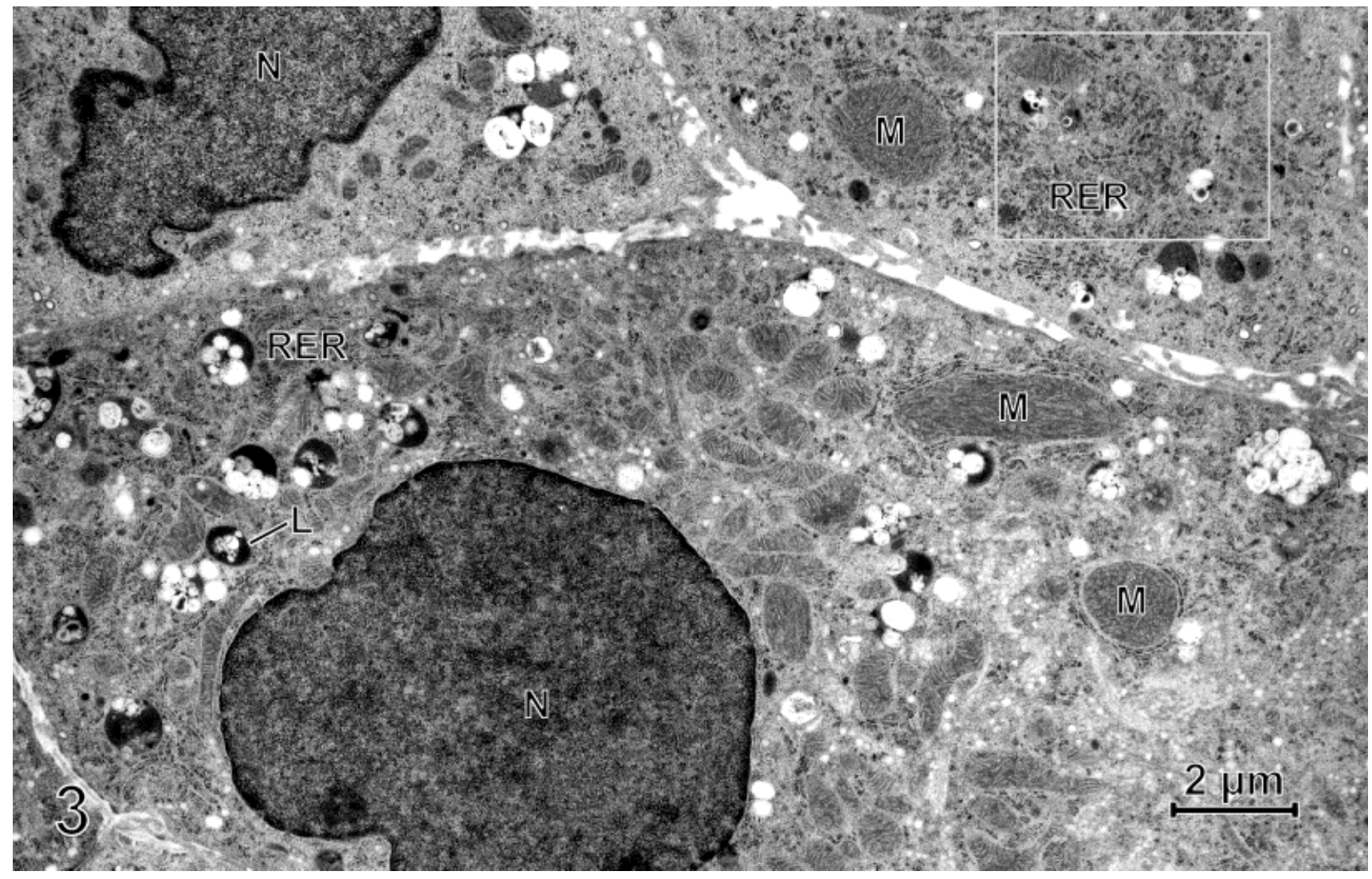

Figs. 2 and 3. Low magnification electron micrographs illustrating examples of the cellular material used in this study, a cultured fibroblast (Fig. 2) and cultured thyroid follicular epithelial cells (Fig. 3). Both cell types exhibit extensive areas of RER. The gray rectangle in each micrograph encloses an area roughly comparable to that shown at higher magnification in Figs. 4 and 5, respectively. Nucleus, N. Mitochondrion, $M$. Lysosome, $L$. The cytoplasm at right in Fig. 2 lacks RER but instead has actin stress fibers $(A)$ and numerous free polysomes.

\section{DISCUSSION}

Most of the large bound polysomes in the cultured thyroid epithelial cells and fibroblasts of this study had an elongated shape resembling that of a hairpin, although probably rounded at both ends. Occasional large spiral polysomes were also observed in both cell types.

\section{Previous Literature}

In his 1958 survey of ribosomes in various cell types, Palade included an el ectron micrograph of cytoplasm from a tissue fibroblast, pointing out three examples of RER surface views that showed "pairs of parallel rows of particles, a pattern frequently encountered in fibroblasts." Movat and Fernando (1962), in a study of fibroblast ultrastructure in several species, showed double rows of ribosomes in occasional RER surface views, an arrangement they interpreted as "tubular structures." They also described "rosette-like" surface views as being equally prominent. Ross and Benditt (1964) found ribosomes grouped in "paired rows" as the most common ribosomal pattern in fibroblasts, and showed that these patterns broke down in guinea pigs afflicted with scurvy, but returned when these animals were treated with ascorbic acid. Goldberg and Green (1964) carried out an ultrastructural study of collagen-secreting fibroblast cell lines from mice. The predominant bound polysomes they saw in RER surface views were "curved chains of up to 10-12 particles." Occasional hairpin bound polysomes were visiblein their figures, but were not mentioned in the article. The polysomes they described were much too small to be making collagen $\alpha$-chains.

There was considerable controversy in the late 1960s about the molecular weight of the thyroglobulin subunit. Several EM studies on thyroglobulin polysomes were carried out, both in vitro and in tissue sections, in an attempt to ascertain the number of ribosomes in the polysome, which would allow an estimate of protein size. The most striking study was that of Keyhani (1969), in sheep thyroid, who demonstrated up to 50 ribosomes per polysome on EM surface views in tissue sections. Three of the figures of that paper showed individual hairpin-bound polysomes similar to those of the present study. However, because the emphasis in Keyhani's paper was on ribosomal number in the polysomes, there was no mention of polysomal shape or organization. Electron micrographs in several other early studies on thyroid follicular epithelial cells included clearcut surface views of hairpin bound polysomes, without comment on their significance (Ekholm and Sjöstrand, 1957, their Fig. 11; Herman, 1960, his Fig. 19; Pantic, 1967, his Fig. 6; Fujita and Honma, 1968, their Fig. 3; Tixier-Vidal et al., 1969, their Figs. 2 and 3a; Fujita, 1974, his Fig. 129). 


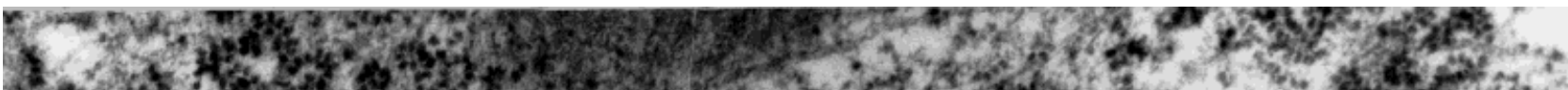

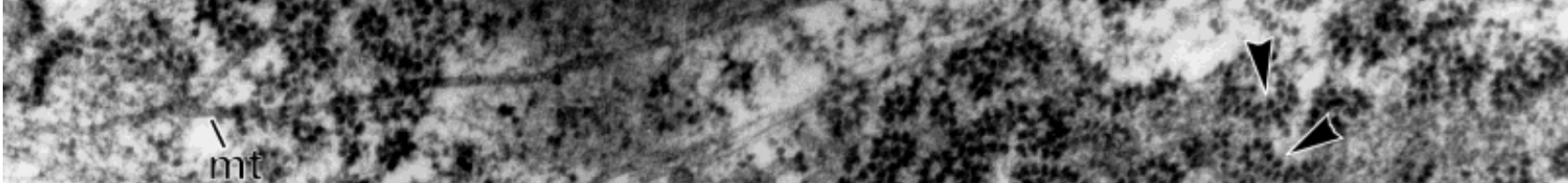

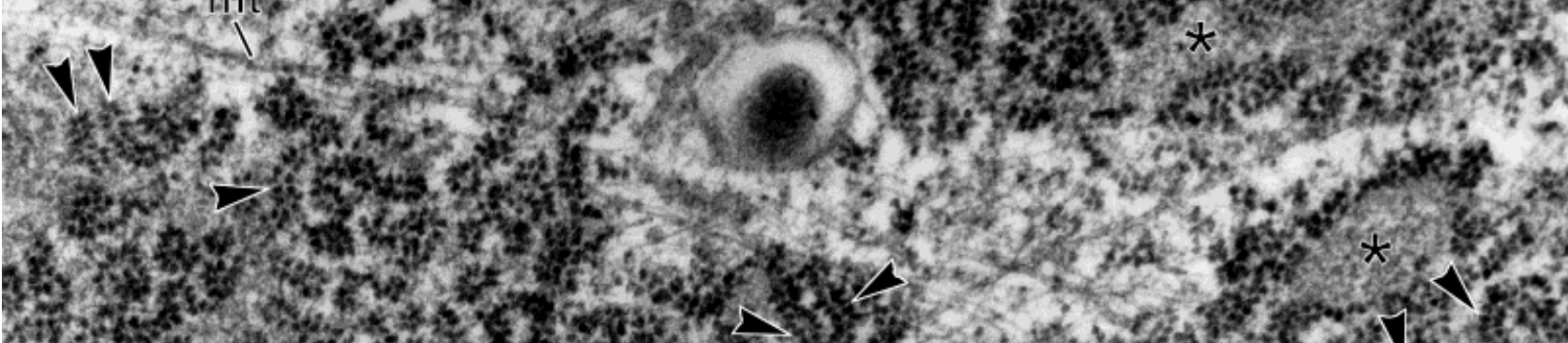



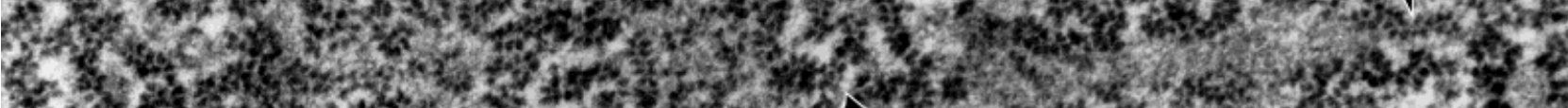

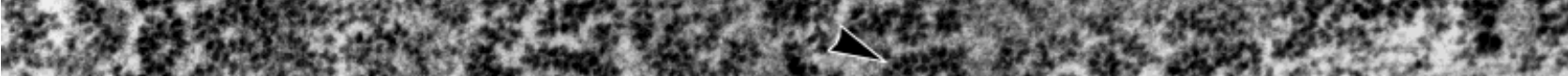



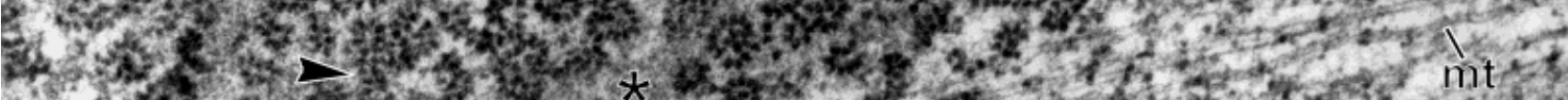



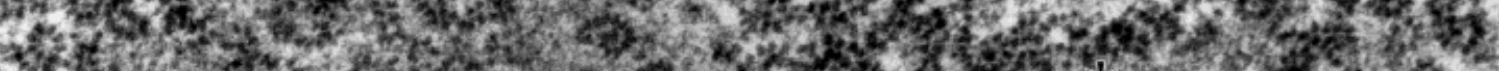

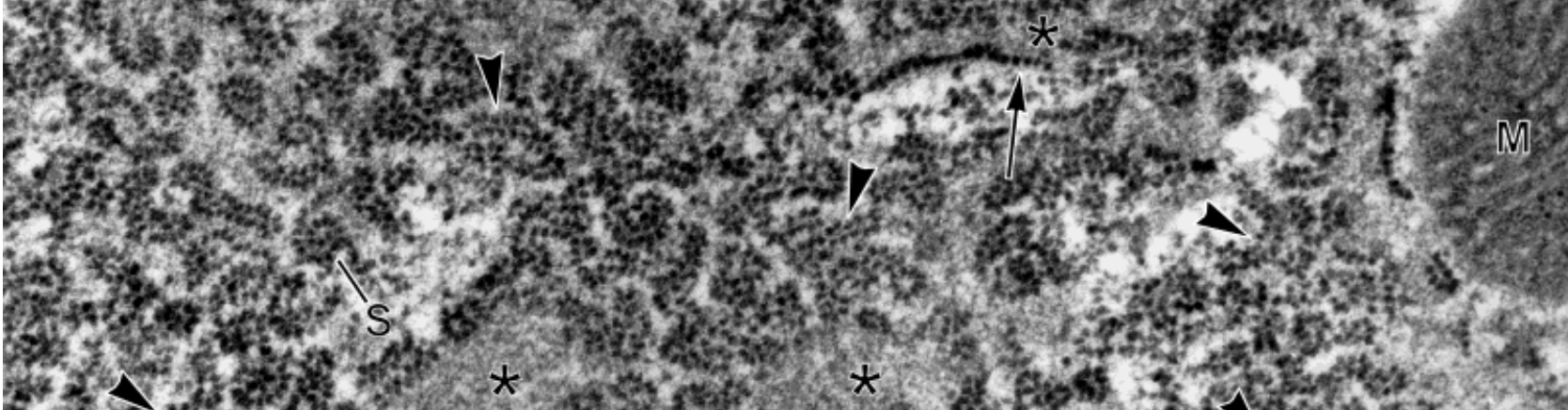
340 ind



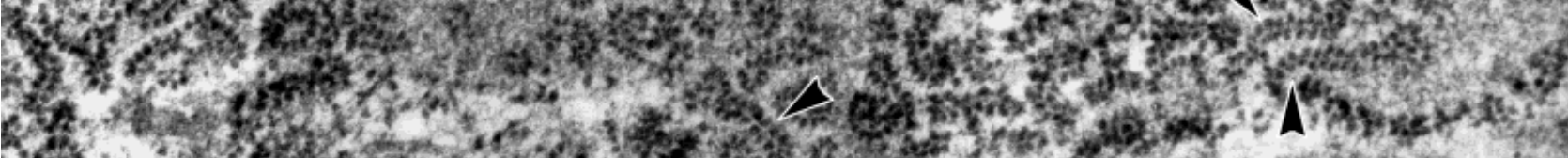

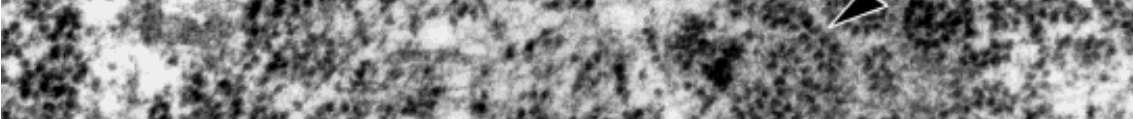

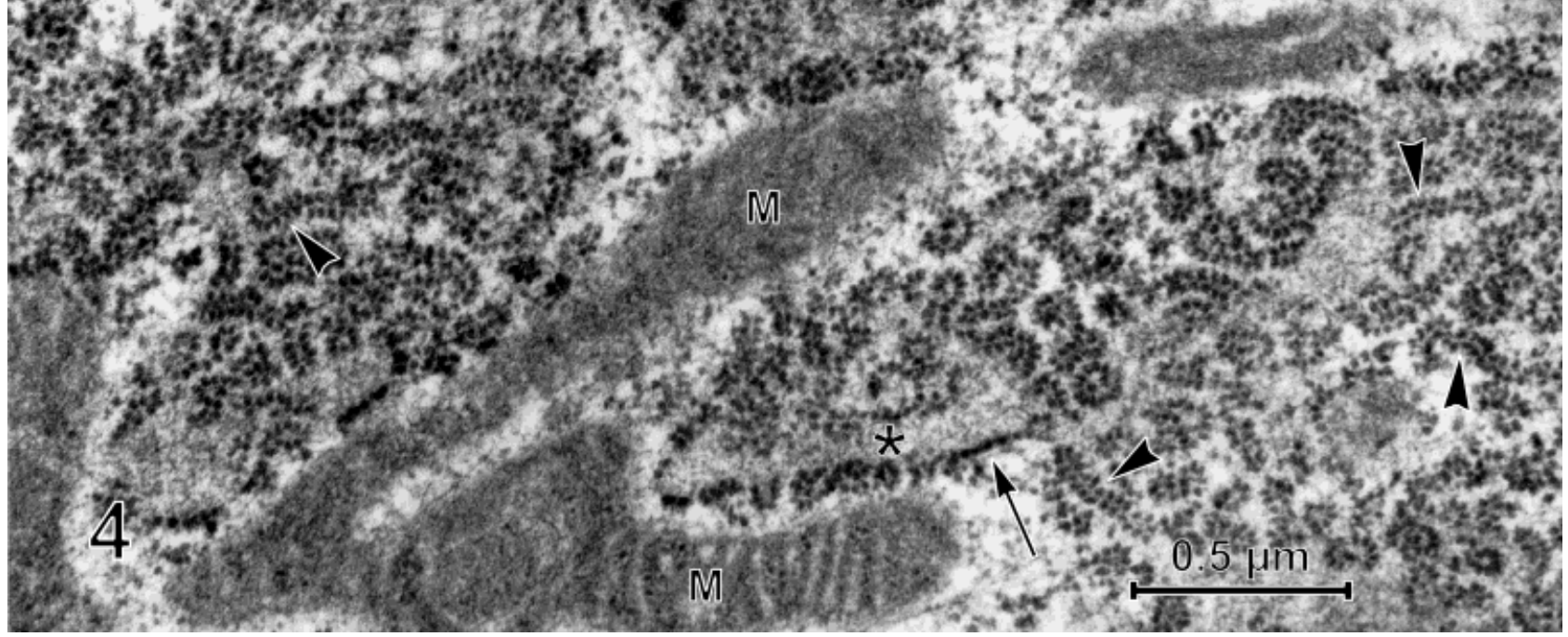

Figure 4. (Legend, overleaf.) 


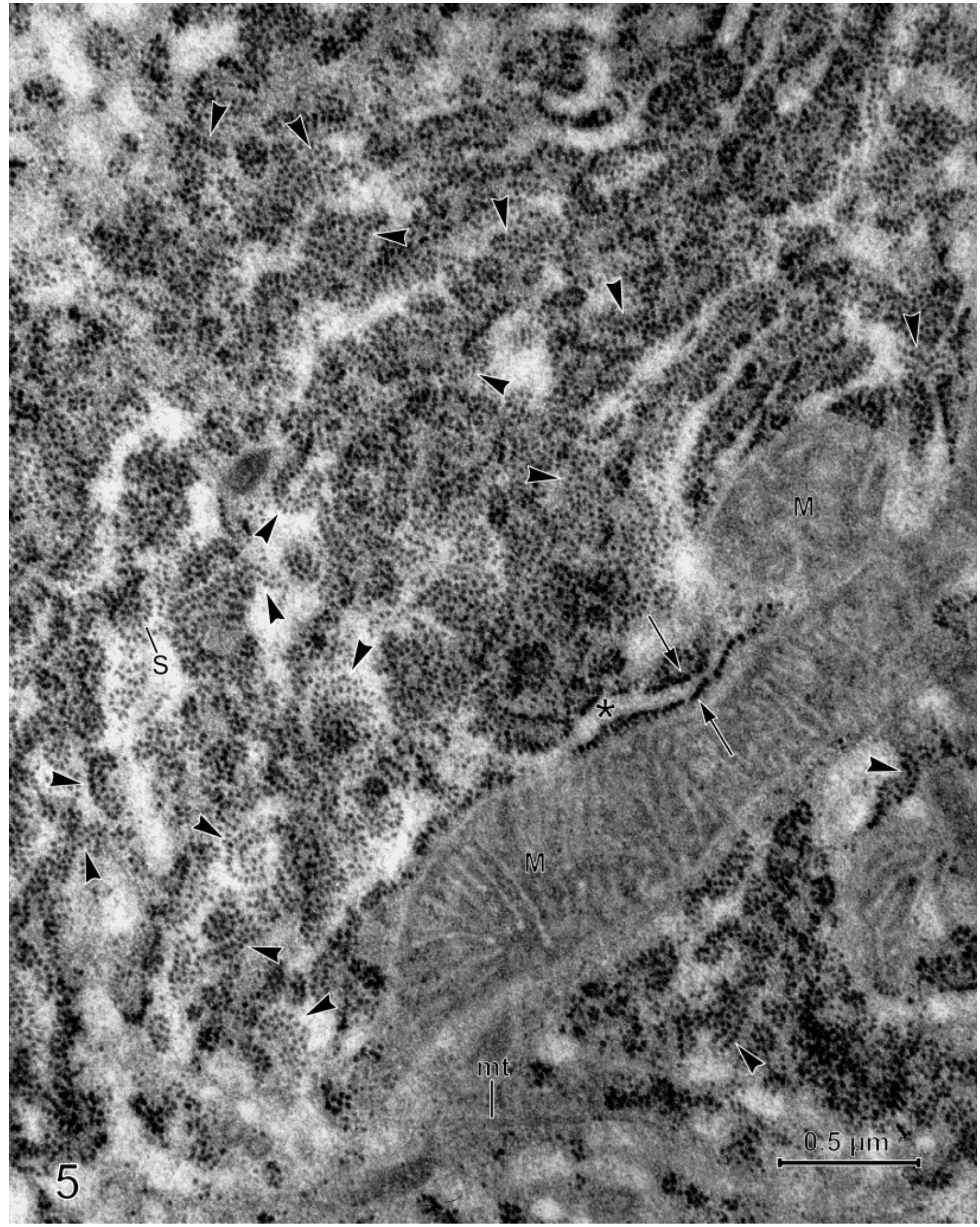

Figs. 4 and 5. Cytoplasm containing abundant RER, showing numerous surface views of bound polysomes, in a cultured fibroblast (Fig. 4) and in a cultured thyroid follicular epithelial cell (Fig. 5). Most of the larger polysomes consist of two parallel rows of ribosomes (arrowheads), as would be expected for hairpin-shaped polysomes. Since the hairpin polysomes are very long, they usually extend out of the plane of section, and so only a portion of each polysome is seen. Occasional large spiral polysomes (S) are sometimes observed. The lumen of the RER often appears expanded (asterisks) in these tangential sections of RER. RER membranes are sometimes seen edge-on (arrows). Mitochondria, $M$. Microtubules, $m t$ 




Figure 6. (Legend, overleaf.)

\section{Identity of the Polysomes}

The abundance of large bound polysomes in both of the cultured cell types of this study would indicate that these cells were producing large proteins in substantial quantity. It is reasonable to assume that the main proteins being made by these large polysomes were the known products of the two cell types.

The preponderant large protein secreted by thyroid follicular epithelial cells is thyroglobulin, a glycoprotein composed of two identical $330 \mathrm{kDa}$ subunits. Thyroglobulin constitutes up to $80 \%$ of the protein in normal mammalian thyroid glands (Shulman et al., 1955). After its synthesis and storage in thyroid follicles, thyroglobulin is subsequently degraded to provide thyroid hormones. The mRNA for human and bovine thyroglobulin subunits has been sequenced, and the mRNA has also been partially characterized in rat and sheep (reviewed by Malthièry et al., 1989). The mRNA is very similar in these four species. 

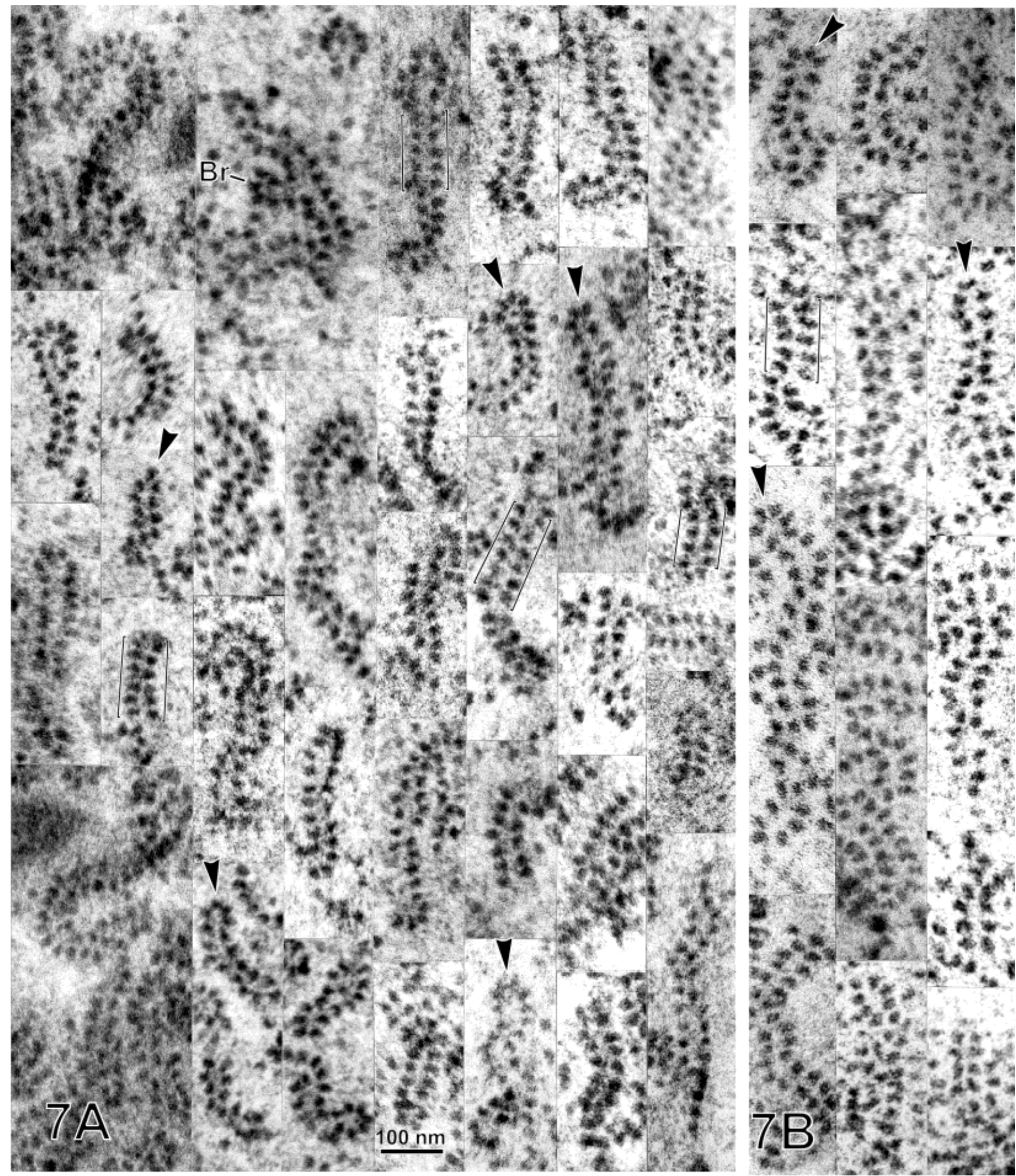

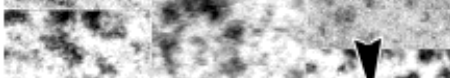



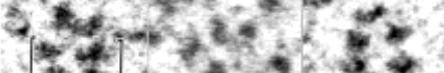

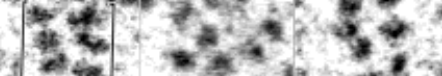

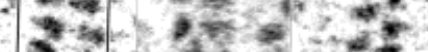
Q * e 3 से $y^{2}=x^{2}+x^{2}+2$

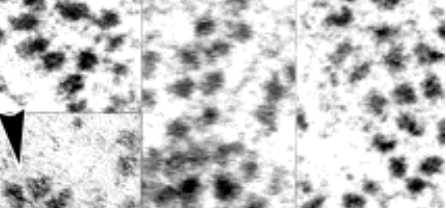


* \& Resaz nos $x^{2} x^{2}=x^{2}+x^{2} x^{2}$

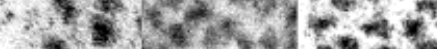

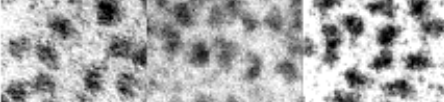
* 6 . 94 \& 6

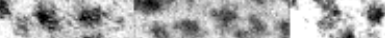

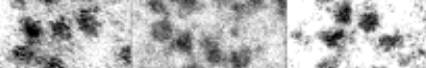

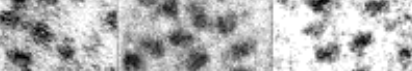
$3 \times 0^{6}>3 \times 20$


$x^{2}+t^{2+3} x^{2}-6 ?$

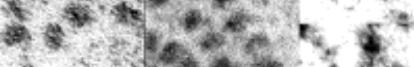

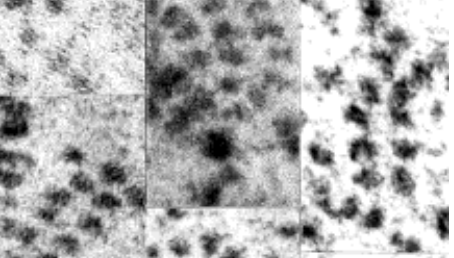

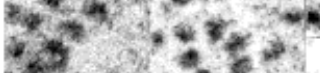

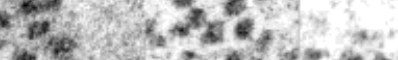



Figs. 6 and 7. Hairpin polysomes seen at higher magnification, from cultured fibroblasts (Fig. 6), from cultured thyroid follicular epithelial cells (Fig. 7A), and from tissue thyroid follicular epithelial cells (Fig. 7B). The polysomes in Figures 6-9 are all shown at the same magnification. The inset to Figure 7 is a diagram (drawn to the same scale) showing the probable appearance of a complete polysome for a prepro- $\alpha$ chain of collagen I, one of the main large proteins produced in quantity by fibroblasts. Examples of closed ends on hairpin polysomes are labeled with arrowheads. Ribosomes in adjacent strands of the polysome sometime appear to be in register (indicated by thin brackets). The hairpin can branch ( $B r$, in Fig. 7A), although this is rarely seen. 


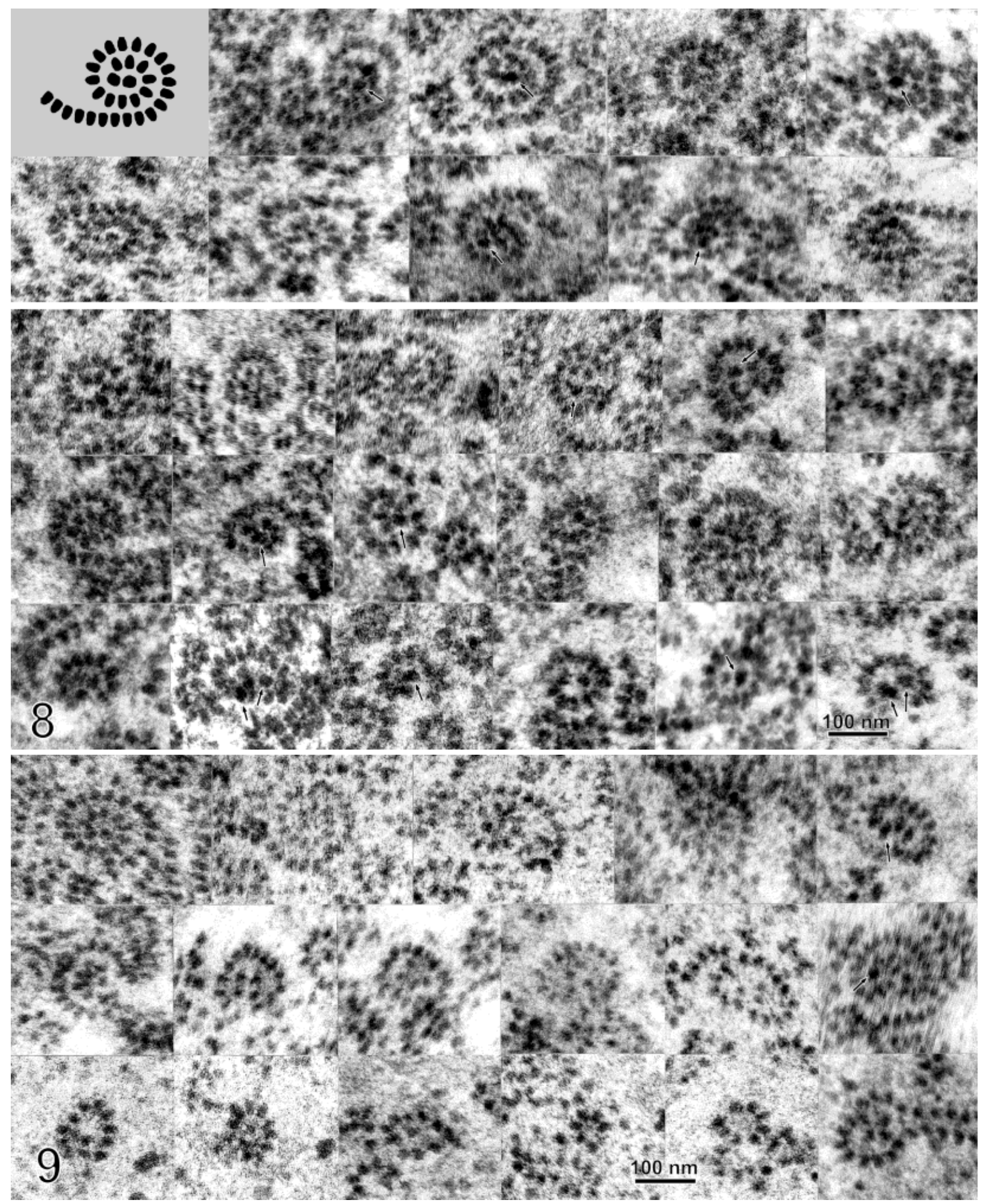

Figs. 8 and 9. Spiral and circular bound polysomes, from cultured fibroblasts (Fig. 8) and from cultured thyroid follicular epithelial cells (Fig. 9 ). These forms are seen less frequently than the hairpin polysomes. The inset to Fig. 8 is a diagram of the large spiral seen occasionally in both cell types; corresponding electron micrographs of the large spiral are seen in the top two rows of Fig. 8 and in the top row of Fig. 9. Particles that are larger and denser than ribosomes are sometimes seen in the center of spiral and circular polysomes (examples are labeled with very small arrows). 


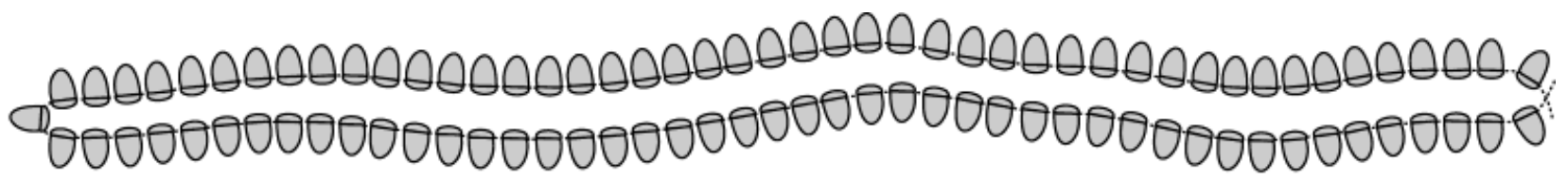

Fig. 10. Diagram of the probable organization of a bound polysome for a thyroglobulin subunit $(330 \mathrm{kDa})$. The approximate number of ribosomes in this polysome is estimated to be about 92 (see text). The figure includes the mRNA, which is usually not visible in electron micrographs of polysome surface views.

The coding region contains 8307 nucleotides in bovine and also in human (van de Graaf et al., 1997). It is probably comparable in the rat. The polysome for thyroglobulin would therefore be expected to contain approximately 92 ribosomes. ${ }^{1}$ The probable appearance of such a thyrogl obulin polysome on the RER membrane, based on the findings of the present study, is diagrammed in Figure 10.

Fibroblasts secrete substantial amounts of collagen (Linsenmayer, 1991; Olsen, 1991). Detailed quantitative studies of collagen synthesis in cultured skin fibroblasts have been carried out in human material, which may be suggestive for the rat cultured dermal fibroblasts of the present study. In cultured human skin fibroblasts (Pinnell, 1985; Geesin et al., 1988), type I collagen constituted about $85 \%$ of collagen production and most of the remainder was type III collagen. Under ascorbate stimulation, collagen synthesis increased three- to fourfold, and its mRNA increased two- to threefold. The synthesis of non-collagen secretory proteins, such as fibronectin, was lower and was unaffected by ascorbate. Prepro- $\alpha$ chains for fibrillar collagens (including collagen types I and III) contain 1360-1515 amino acids (Vuorio and de Crombrugghe, 1990). Therefore, their polysomes would be expected to have approximately 45-50 ribosomes. $^{1}$ The likely appearance of a collagen polysome is drawn as an inset to Fig. 6 .

\section{Shape Consistency and Maintenance}

In this study, the great majority of large bound polysomes were hairpin-shaped in thyroid epithelial cells, source of thyroglobulin, and also in fibroblasts, presumably making mainly prepro- $\alpha$ chains of collagen I. The polysomes for these proteins would therefore seem to have a relatively consistent shape. This conclusion agrees with other studies in which the shape of bound polysomes has been studied in cell types that secrete large quantities of a particular protein, allowing the assumption that a majority of the observed bound polysomes were producing that protein. Kitani et al. (1982) described bound polysomes in human myeloma cells making various classes of immunoglobulins. Observations on polysome surface views in IgG

\footnotetext{
${ }^{1}$ The approximate number of ribosomes that would be expected in the polysome for a particular protein can be predicted on the basis of one ribosome per 90 nucl eotides of mRNA (Staehelin et al., 1964). For proteins of appreciable size this would be roughly the same as one ribosome per 90 nucleotides in the mRNA coding region, or per 30 amino acids in the nascent preprotein. The number of ribosomes can also be estimated in terms of one ribosome per 3,000 Da in the final protein (see De Nayer and Labaw, 1971). For example, in our previous study (Christensen et al., 1987), a peak of about 7 ribosomes was observed for bound polysomes in cells making growth hormone, a molecule of $22 \mathrm{kDa}$ (thus $3142 \mathrm{Da} /$ ribosome), and with an mRNA coding region (Seeburg et al., 1977) of 648 nucleotides (93 coding region nucleotides/ribosome).
}

myel oma cells from 14 patients yiel ded two main classes of bound polysomes, one containing 17-18 ribosomes and the other with 7 ribosomes. The larger polysome, presumably making the IgG heavy chain, was a circle of about 14 ribosomes with 3-4 additional ribosomes in the center of the circle. The smaller polysome, probably for the light chain, was a circular polysome of 7 ribosomes. In our previous study of pituitary cells making either growth hormone or prolactin (Christensen et al., 1987), most of the bound polysomes were small circles of 6-7 ribosomes, again suggesting a consistent polysomal form. As still another example, the study of polysome surface views in gland cells of chick oviduct (Palmiter et al., 1970), secreting mainly ovalbumin, showed a predominance of spiral polysomes containing about 13 ribosomes. These various studies suggest that bound polysomes making a particular protein maintain a relatively consistent shape.

How is the shape maintained? It is likely that shape maintenance in bound polysomes involves two factors: (1) a natural tendency of mRNA in polysomes to bend, and (2) some unknown spacer component in larger polysomes that would maintain the distance between strands.

It is well established that polysomal mRNA has a natural tendency to bend. When Shelton and Kuff (1966) brought small free polysomes down on an EM grid membrane, the polysomes spontaneously assumed the same circular shape exhibited by small circular bound polysomes that are observed in surface views of the RER in tissue sections. The direction of the bend relative to ribosomal orientation on the mRNA, with the small subunit lying in the curve, was the same in the spontaneous circles formed by Shelton and Kuff (1966) described above and in bound polysomes viewed by negative staining on rough microsome vesides (Christensen, 1994). This suggests that the bend may be due to the curved path of the mRNA within each ribosome, which occurs in the same direction (Agrawal et al., 1996).

Thetendency of polysomal mRNA to bend is probably an adequate explanation for the shape of small circular and spiral bound polysomes. However, it doesn't account for the shape of hairpin polysomes, which are the most common large bound polysomes in the cell types of the present study, nor does it explain the shape of large spiral bound polysomes, in which a regular spacing is maintained between successive strands in the spiral. In fact, as can be seen in Fig. 11, this regular spacing between strands is a characteristic feature shared by both the hairpin and the large spiral polysome. This suggests a model in which adjacent strands of the mRNA in large bound polysomes would be maintained at a relatively constant distance from one another by some spacing mechanism, perhaps involving membrane proteins of the RER. 

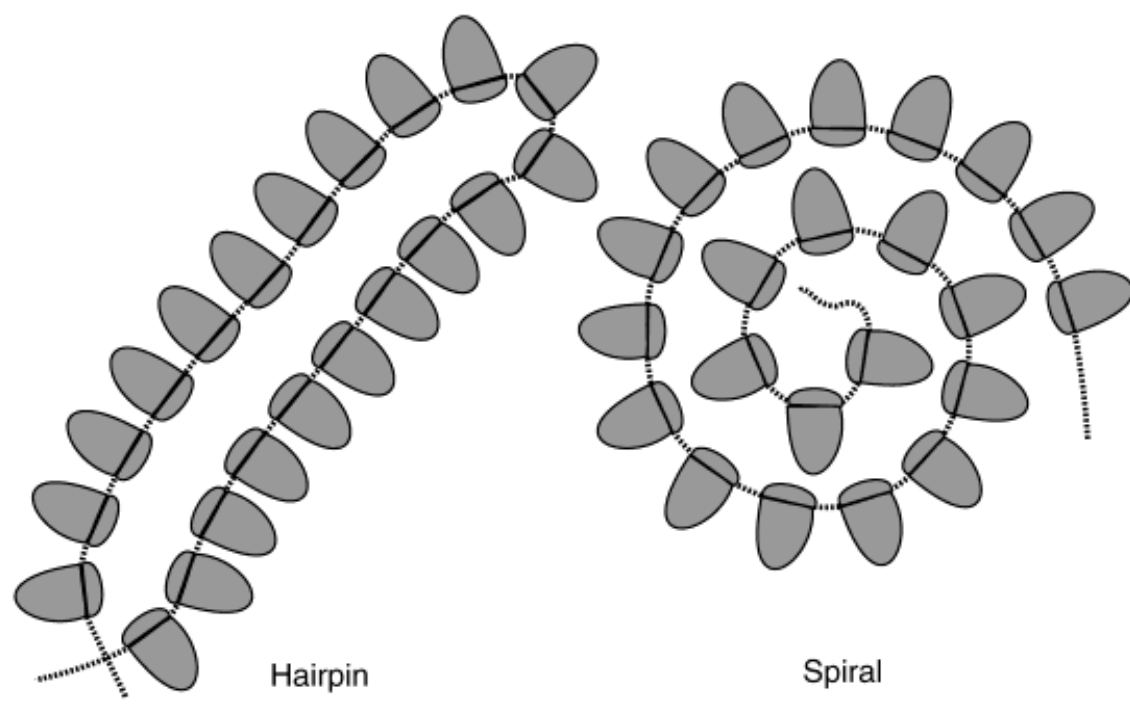

Fig. 11. Diagram comparing hairpin and spiral bound polysomes. The mRNA, indicated by a dotted line, is arranged as suggested in our previous study (Christensen, 1994). The $5^{\prime}$ and $3^{\prime}$ ends of the mRNA are shown at one end of the hairpin polysome, but may be elsewhere. For possible functional implications of these shapes, see the text.
If one postulates such a spacing mechanism, then the hairpin and large spiral bound polysomes (Fig. 11) would be seen as two different arrangements of long polysomal strands on the RER membrane that would utilize the spacer mechanism to form a compact, regular polysomal shape. In the large spiral bound polysome, the curvature of the spiral would result from the mRNA's tendency to bend, and the spacing mechanism would keep successive strands at a consistent spacing. In the hairpin polysome, on the other hand, each strand's tendency to bend would be directed toward the other strand, thus canceling out, and the spacer mechanism would maintain a uniform interstrand distance.

As can be seen in Fig. 11, the spacer mechanism would need to be capable of functioning equally well when ribosomes in the two adjacent strands are "back-to-back" (as they are in the hairpin) or "front-to-back" (as in the large spiral). This would suggest that the spacer does not interact directly with ribosomes, but rather with the translocon that underlies each ribosome (see Matlack et al., 1998; Beckmann et al., 1997). Each of these protein translocation pores in the RER membrane is made up primarily of 3-4 Sec61 complexes that encircle the pore. If the binding sites at each end of the spacer component were capable of binding to Sec61 complexes, then the spacer could attach equally well to any side of the translocon.

The possible length of the proposed spacer component may be estimated by measuring the distance between the probable position of translocons (Beckmann et al., 1997; Christensen, 1994) in adjacent strands of hairpin polysomes observed in surface view. Such measurements suggest a spacer length of approximately $35 \mathrm{~nm}$. The spacer might be composed of one or more membrane proteins.

\section{Some Possible F unctional Correlations}

The relatively constant center-to-center distance between ribosomes in these polysomes, averaging $24.9 \mathrm{~nm}$ in the present study, allows an estimation of how much the mRNA is contracted. Within that center-to-center distance there would be about 90 mRNA nucleotides (Staehelin et al., 1964), which would give a length of $0.28 \mathrm{~nm}$ per nucleotide in the strand. However, in a fully-extended mRNA strand, one would expect each nucleotide to have a length of about $0.59 \mathrm{~nm}^{2}$ Thus, the mRNA strand appears to be contracted to about half of its fully extended length, presumably by internal base pairing, protein interactions, and by the curved path of the mRNA within each ribosome.

The regular spacing between ribosomes in these large bound polysomes implies a consistent rate of initiation and elongation during translation. If these processes were irregular, then we would expect prominent gaps and clustering of ribosomes al ong the polysomal strands. Hairpin polysomes did not exhibit any appreciableclustering of ribosomes that might suggest "ribosomal pausing" (Wolin and Walter 1993; Nakahara et al., 1994), which involves a local arrest in protein synthesis, causing ribosomes to accumulate on the upstream side of the pause. However, the dense particles that were sometimes seen in the center of circular or spiral polysomes (see small arrows in Figs. 8 and 9) could be interpreted as two or more ribosomes tightly pressed together. On the other hand, similar dense particles within bound polysomes have been interpreted by Kitani (1982) as "ribosomes with an adhering amorphous substance."

In the hairpin polysomes observed in this study, ribosomes often appear to be paired with their neighbor in the adjacent strand (see thin brackets in Figs. 6 and 7). Ross and Benditt (1964) also alluded to this arrangement in mentioning "rows of paired ribosomes." This tendency for ribosomes on opposing strands to be in register might reflect an interstrand binding by spacer components, as is postulated above. If such a cross-strand linkage between ribosomes (or their translocons) occurs, possibly maintaining the spacing between strands, the binding might be transitory, with little practical effect on translation. On the other hand, if the binding is relatively stable, then it could limit the ability of the ribosomes to move during transla-

IIn RNA, the sugar (furanose) groups have a $\mathrm{C}_{3^{\prime} \text {-endo puckering }}$ (Saenger, 1984), yielding a nucleotide length (phosphorus to phosphorus) of $\sim 0.59 \mathrm{~nm}$ (Sundaralingam, 1974, page 83). It is difficult to evaluate any possible fol ding tendency between nucleotides along the extended strand, which might shorten the effective length per nucl eotide somewhat. 
tion. Since translation proceeds in opposite directions in the two adjacent strands, the linked ribosomes would then be essentially immobile, and only the mRNA would be free to move during translation. If this were the case, then the $5^{\prime}$ and $3^{\prime}$ ends of the mRNA could be anywhere in the hairpin, and not restricted to one of its ends, as has been drawn in Figs. 10 and 11. It should be pointed out that the dynamics of translation could be quite different in a large spiral polysome, where translation is proceeding in the same direction in adjacent strands.

Interactions between the 5' and 3' untranslated regions of $\mathrm{mRNA}$ may be important in the initiation and regulation of protein synthesis as well as in mRNA turnover (Decker and Parker, 1995; Wickens et al., 1997; Preiss et al., 1998). This interaction of the mRNA ends is easy to imagine for free polysomes, which are flexible in three dimensions. In bound polysomes, on the other hand, the ribosomes are tightly attached to the RER membrane and so are confined to a two-dimensional plane, causing the ends to have considerably less flexibility. Nevertheless, the shape of circular and hairpin bound polysomes would put the $5^{\prime}$ and $3^{\prime}$ ends in proximity, allowing interactions. On the other hand, in large spiral bound polysomes, such as those shown in the present study (Figs. 8 and 9), the two ends of the mRNA would lie a considerable distance from each other, making it less likely that the 5' and 3 ' ends could interact effectively (see Fig. 11).

\section{ACKNOWLEDGMENTS}

We thank Terry Lowry for his help in printing the micrographs and assembling the composite figures.

\section{LITERATURE CITED}

Agrawal RK, Penczek P, Grassucci RA, Li YH, Leith A, Nierhaus KH, Frank J . 1996. Direct visualization of $A_{-}, P_{-}$, and $E$-site transfer RNAs in the Escherichia coli ribosome. Science 271:1000-1002.

Ambesi-Impiombato FS, Parks LAM, Coon HG. 1980. Culture of hormone-dependent functional epithelial cells from rat thyroids. Proc Natl Acad Sci USA 77:3455-3459.

Ambesi-Impiombato FS, Perrild H, editors. 1989. FRTL-5 today. Amsterdam: Elsevier Science Publishers B.V.

Beckmann R, Bubeck D, Grassucci R, Penczek P, Verschoor A, Blobel $G$, Frank J . 1997. Alignment of conduits for the nascent polypeptide chain in the ribosome-sec61 complex. Science 278:2123-2126.

Christensen AK. 1991. The bound polysomes of cultured fibroblasts have predominantly a hairpin shape. J Cell Biol 115:72a (abstract).

Christensen AK. 1994. Negatively-stained polysomes on rough microsome vesicles viewed by electron microscopy: further evidence regarding the orientation of attached ribosomes. Cell Tissue Res 276:439-444.

Christensen AK, Coon HG. 1990. Organization of the thyroglobulin polysome, studied in EM surface views of rough endoplasmic reticulum in cultured rat thyroid cells. In: Peachey LD, Williams DB, editors. Electron microscopy 1990, Proc XII Int Congr Electron Microsc (Seattle). San Francisco: San Francisco Press. p 546-547 (abstract).

Christensen AK, Kahn LE, Bourne CM. 1987. Circular polysomes predominate on the rough endoplasmic reticulum of somatotropes and mammotropes in the rat anterior pituitary. AmJ Anat 178:1-10.

Decker CJ , Parker R. 1995. Diversity of cytoplasmic functions for the 3' untranslated region of eukaryotic transcripts. Curr Opin Cell Biol 7:386-392.

De Nayer P, Labaw LW. 1971. Identification of large sized polyribosomes in bovine thyroid glands. Endocrinology 88:783-786.

Ekholm R, Sjöstrand FS. 1957. The ultrastructural organization of the mouse thyroid gland. J Ultrastructure Res 1:178-199.

Fujita H. 1974. Thyroid gland. In: Kurosumi K, Fujita H, editors. An atlas of electron micrographs, functional morphology of endocrine glands. Tokyo: I gaku Shoin Ltd. p 189-239.

Fujita H, Honma Y. 1968. Some observations on the fine structure of the endostyle of Iarval lampreys, ammocoetes of Lampetra japonica. Gen Comp Endocrinol 11:111-131.

Geesin J C, Darr D, Kaufman R, Murad S, Pinnell SR. 1988. Ascorbic acid specifically increases type I and type III procollagen messenger RNA levels in human skin fibroblast. J I nvest Dermatol 90:420-424.

Goldberg B, Green H. 1964. An analysis of collagen secretion by established mouse fibroblast lines. J Cell Biol 22:227-258.

Herman L. 1960. An electron microscope study of the salamander thyroid during hormonal stimulation. J Biophys Biochem Cytol 7:143-150.

J epsen A, MacCallum DK, Lillie J H. 1980. Fine structure of subcultivated stratified squamous epithelium. Exp Cell Res 125:141-152.

Keyhani E. 1969. Présence de longs polysomes dans la thyroïde de mouton. Etude par la technique de coupes et coloration positive. C R Acad Sc Paris, series D 269:1885-1888.

Kitani T, Yonezawa T, Imanaka T, Hiraoka A, Nasu T. 1982. UItrastructural analysis of membrane-bound polysomes in human myeloma cells. Blut 44:51-63.

Linsenmayer TF. 1991. Collagen. In: Hay ED, editor. Cell biology of extracellular matrix, 2nd ed. New York: Plenum Press. p 5-37.

Malthièry $Y$, Marriq $C$, Bergé-Lefranc J -L, Franc J -L, Henry $M$, Lejeune P-J , Ruf J , Lissitzky S. 1989. Thyroglobulin structure and function - recent advances. Biochimie (Paris) 71:195-210.

Matlack KES, Mothes W, Rapoport TA. 1998. Protein translocation: tunnel vision. Cell 92:381-390.

Mollenhauer HH. 1964. Plastic embedding mixtures for use in electron microscopy. Stain Technol 39:111-114.

Movat HZ, Fernando NVP. 1962. The fine structure of connective tissue. I. The fibroblast. Exp and Mol Path 1:509-534.

Nakahara DH, Lingappa VR, Chuck SL. 1994. Translocational pausing is a common step in the biogenesis of unconventional integral membrane and secretory proteins. J Biol Chem 269:7617-7622.

Olsen BR. 1991. Collagen biosynthesis. In: Hay ED, editor. Cell biology of extracellular matrix, 2nd ed. New York: Plenum Press. p 177-220.

Palade GE. 1955. A small particulate component of the cytoplasm. J Biophys Biochem Cytol 1:59-68.

Palade GE. 1958. A small particulate component of the cytoplasm. In: Palay SL, editor. Frontiers in cytology. New Haven: YaleUniv. Press. p 283-304.

Palmiter RD, Christensen AK, Schimke RT. 1970. Organization of polysomes from pre-existing ribosomes in chick oviduct by a secondary administration of either estradiol or progesterone. J Biol Chem 245:833-845

Pantic V. 1967. Ultrastructure of deer and roe-buck thyroid. Z Zellforsch 81:487-500.

Pinnell SR. 1985. Regulation of collagen biosynthesis by ascorbic acid: a review. YaleJ Biol Med 58:553-559.

Preiss T, Muckenthaler M, Hentze MW. 1998. Poly(A)-tail-promoted translation in yeast: implications for translational control. RNA 4:1321-1331.

Reynolds EJ. 1963. The use of lead citrate at high $\mathrm{pH}$ as an electron-opaquestain in electron microscopy.J Cell Biol 17:208-212.

Ross R, Benditt EP. 1964. Wound healing and collagen formation. IV. Distortion of ribosomal patterns of fibroblasts in scurvy. J Cell Biol 22:365-389.

Saenger W. 1984. Principles of nucleic acid structure. New York: Springer-Verlag.

Seeburg PH, Shine J, Martial J A, Baxter J D, Goodman HM. 1977. Nucleotide sequence and amplification in bacteria of structural gene for rat growth hormone. Nature 270:486-494.

Shelton E, Kuff EL. 1966. Substructure and configuration of ribosomes isolated from mammalian cells. J Mol Biol 22:23-31.

Shulman S, Rose NR, Witebsky E. 1955. Studies on organ specificity. III. Ultracentrifugal and electrophoretic examinations of thyroid extracts. J I mmunol 75:291-300.

Staehelin T, Wettstein FO, Oura H, Knoll H. 1964. Determination of the coding ratio based on molecular weight of messenger ribonucleic 
acid associated with ergosomes of different aggregate size. Nature 201:264-270.

Sundaralingam M. 1974. Evolution of conformational principles in nucleic acids. Intern J Quantum Chem, Quantum Biol Symposium No 1:81-91.

Tixier-Vidal A, Picart R, Rappaport L, Nunez J . 1969. Ultrastructure et autoradiographie de cellules thyroidiennes isolées, incubées en présence de 125. J Ultrastucture Res 28:78-101.

van de Graaf SAR, Pauws E, Devijlder J J M, Risstal pers C. 1997. The revised 8307 base pair coding sequence of human thyroglobulin transiently expressed in eukaryotic cells. Eur J Endocrinology 136:508-515.

VuorioA, de Crombrugghe B. 1990. The family of collagen genes. Annu Rev Biochem 59:837-872.

Wickens M, Anderson P, J ackson RJ . 1997. Life and death in the cytoplasm: messages from the $3^{\prime}$ end. Curr Opin in Genet Develop 7:220-232.

Wolin SL, Walter P. 1993. Discrete nascent chain lengths are required for the insertion of presecretory proteins into microsomal membranes. J Cell Biol 121:1211-1219. 